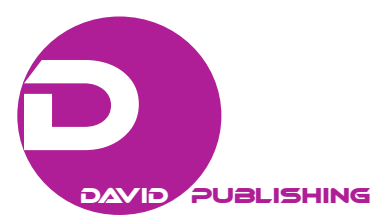

\title{
Healthy Business Environment According to the General Theory of Sustainable Development
}

\author{
Antonín Moravec \\ Philosophy and Management of Innovation Institute, Prague, Czech Republic
}

\begin{abstract}
The article continues thinking about prospective of human society. Is the healthy business environment a fiction or a real opportunity? How far-reaching are the roots of the future natural processes of changes? How to work with the current global economic models? Can the current European integration process be considered as natural? Is a weak state a new opportunity for a future strong economy? What is the historical essence of the liberal thought? Why the current economic models are not permanent, why are they not sustainable, and why are they not developing for the basic quantum, which is the man as an individual? Can also the basic quantum be integration units as family, society, company, municipality, region, country, or EU, etc.? Qualified answers to the questions can be seen in a theoretical context of the General Theory of the Sustainable Development (GTSD), too. Theoretical trinity of GTSD is based on three theoretical pillars: GPT (Gravitation Polarity Theory), QET (Quantum Economy Theory), and BIT (Big Integration Theory). They can be considered as relevant theoretical basics for historical, current, and future sustainable development process. The healthy business environment is based on the healing of man. In GTSD, businessman and man gain a new source of knowledge, a new natural relationship, and a new content. This is a responsibility towards the customer and towards the partner in business. Businessman's profit speaks about a new business in natural partnerships. Sustainable development without the Groove Management (second generation management) and without the fourth Reformation (with second generation of innovation) is a process that only reflects the regressive trend that takes place for more than 6000 years. Without the new content of the Fifth Theoretical Dimension (Consciousness) the historical mainstream of sustainable development process cannot be grasped. The biggest risk for the expected Healthy business society is a contemporary slave communism and contemporary crazy capitalism. Feasibility of business models of healthy business doing societies stands not only on adequate theoretical basis, but also on predicted cannibalism between slave communism and crazy capitalism. The biggest current risk of healthy business environment is a political arbitrariness, the desire for power, and the desire for money-corruption.
\end{abstract}

Keywords: healthy business doing society, Groove management and Stowaway management, crazy capitalism and slave communism, natural spontaneous order, consciousness as the new fifth theoretical dimension

\section{Introduction}

Antonín Moravec, Ph.D., Head of Institute, Philosophy and Management of Innovation Institute, Trident Development, Prague, Czech Republic.

Correspondence concerning this article should be addressed to Antonín Moravec, Philosophy and Management of Innovation Institute, Trident Development, Jankovcova 2, 17000 Prague, Czech Republic. Mobile: +420774816955. E-mail: institute@tridentprague.eu; moravec10@centrum.cz. 
The current economic model can rather be compared to "crazy capitalism" and it's "Stowaway management". The problem is not a market economy. The problem is a foolishness that enslaved Europe after the French revolution. The problem is the current ideologies in the consciousness of man.

How do people recognize a healthy business environment from a sick business environment? This paper offers a Groove management system as a healing tool not only for the business environment. Groove management is a systemic therapy tool for any environment, for environment of man as an individual, for family, for business, for companies, for municipalities, for states, for EU, etc..

Groove management pushes a management institute in the field of art. Manager as an orchestra player composes music for his managerial activity himself.

The theoretical basis of Groove management is the General Theory of Sustainable Development (GTSD).

The function of the spiral between the environment of a crazy market and the environment of sustainable development consists of the reformation.

Reformation is a part of European history. Europe of the 21st century will be Europe of the fourth Reformation and at the same time the third Czech Reformation.

\section{Literature Review}

The theoretical bases are: works by Smith (2001), Pavlík (2001), Drucker (2001), and Friedman (1962); the general theory of relativity; quantum theory; general theory of sustainable development (Figure 1) by Moravec (2004, 2006, 2012, 2013); and "string" theory.

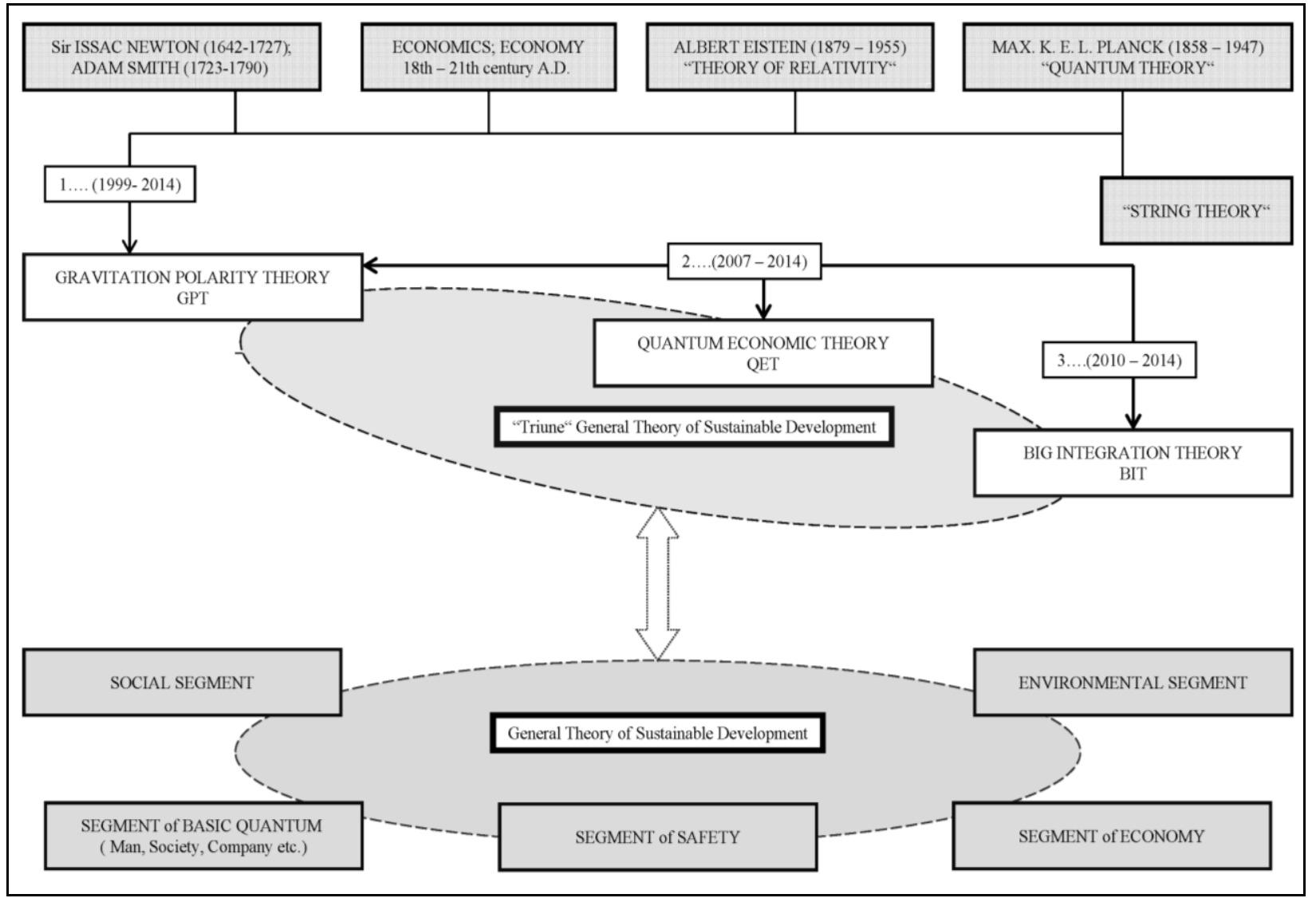

Figure 1. Sustainability on theoretical and applicable contexts. 


\section{Research}

\section{General Theory of the Sustainable Development-GTSD}

A characteristic feature of the GTSD is its theoretical trinity:

- Gravitation polarity theory: the understanding of the change processes in bipolar environments and in cycles. These are closed human concepts on one hand and the order (the natural spontaneous order) on the other;

- Quantum economy theory: description of the process relations between the NSO and PSO. NSO and PSO are a one meaningful whole and institute of elementary particles Adapa;

- Big integration theory: It proves the existence regularities of the unique relationship of NSO and PSO; fifth dimension - consciousness; it opens new research area for natural, social, and human sciences.

Since the GTSD was first presented on 22 August 2012, it is essential to introduce scientific and professional community for the terminology used in GTSD: NSO - Natural Spontaneous Order, GTSD - General Theory of Sustainable Development, PO—Positive Order, POE—Positive Order Environment, PSO—Positive Spontaneous Order, NSOE-Natural Spontaneous Order Environment, PSOE-Positive Spontaneous Order Environment, MNSO - Management of Natural Spontaneous Order, GM-Groove Management (Management of Positive Spontaneous Order), CNSO - Consciousness NSO, CPSO - Consciousness PSO, and CI-Cycle Index.

\section{Comment on Figures (2-8)}

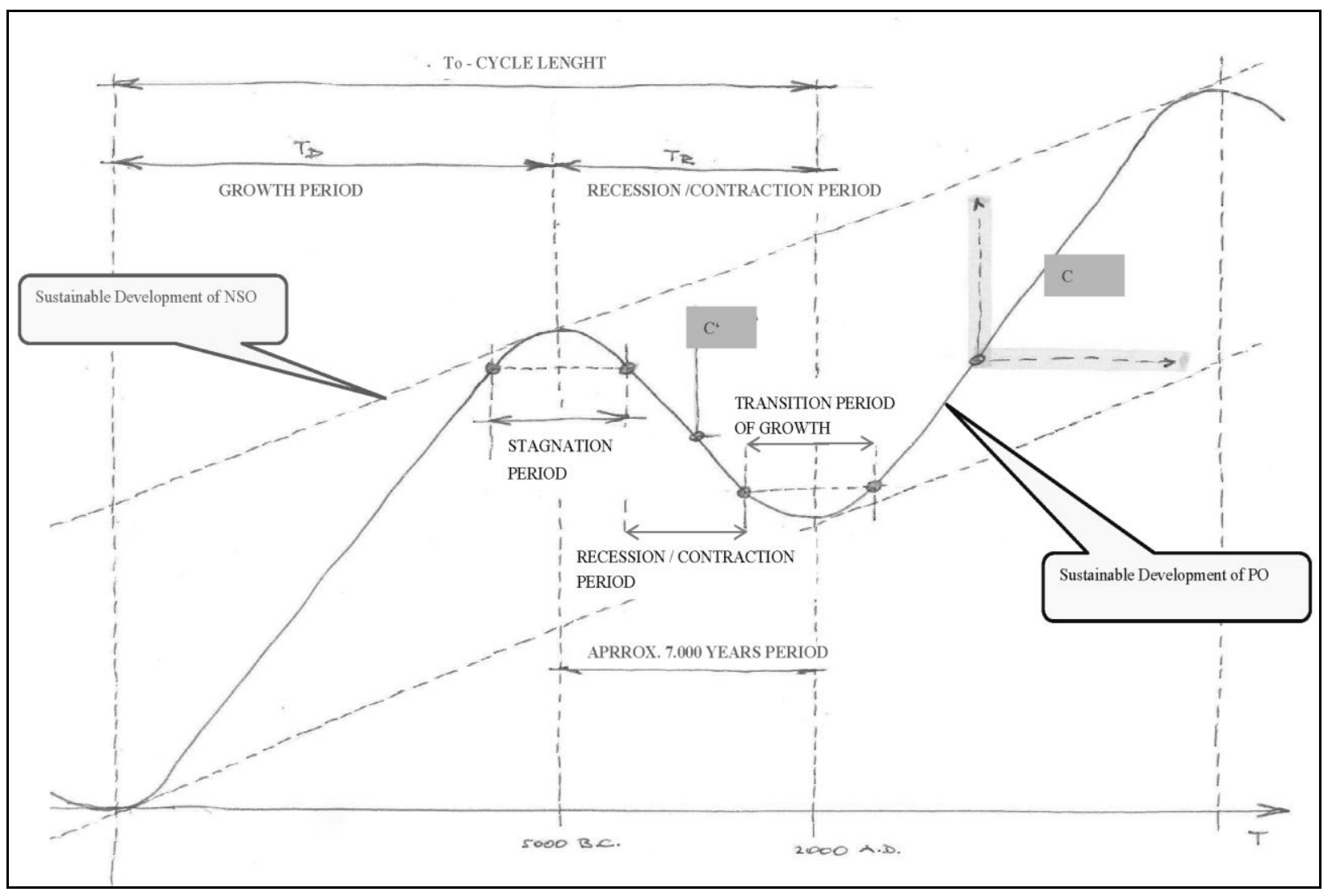

Figure 2. Gravitation Polarity Theory in a time perspective of 30,000 years model. 


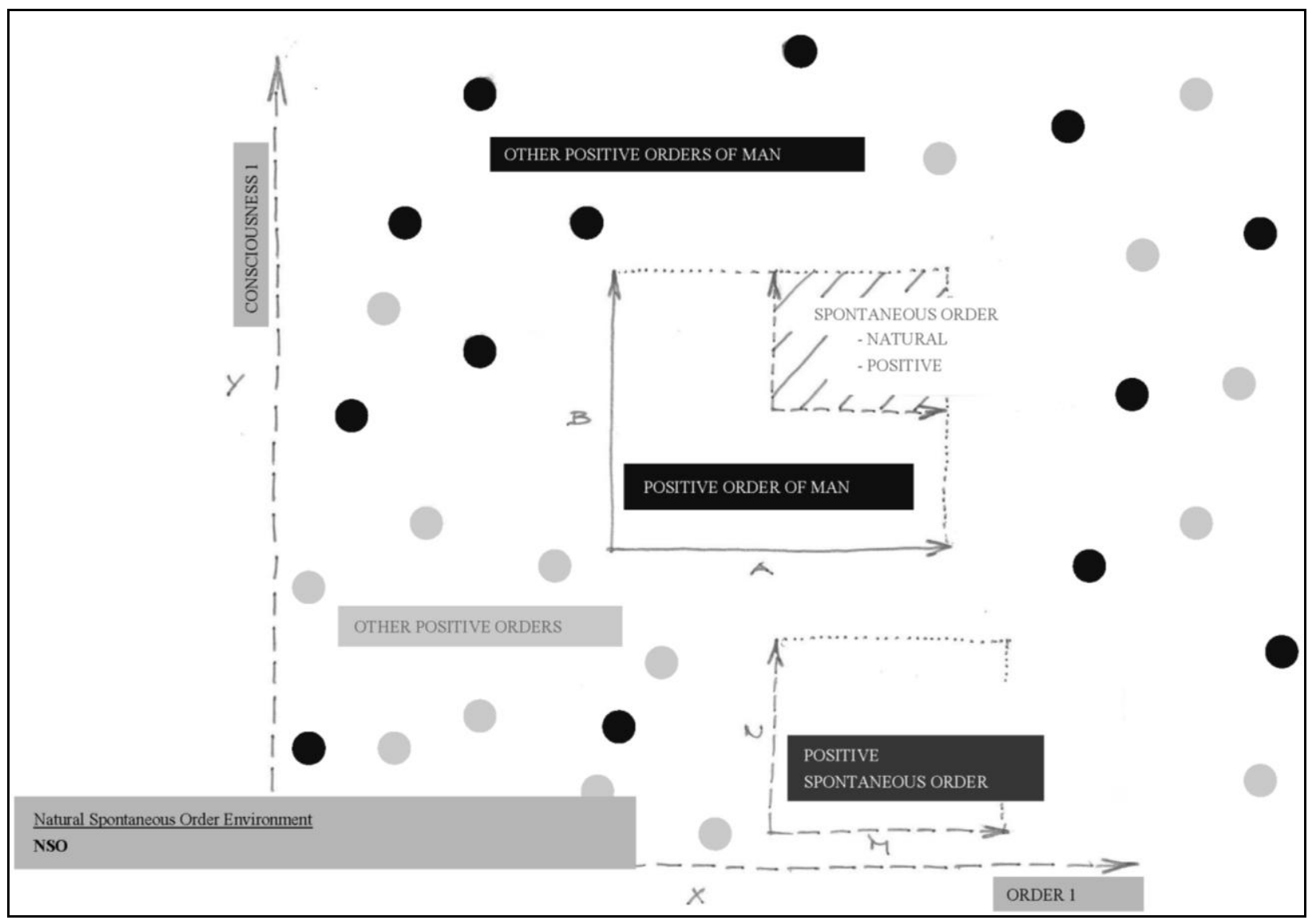

Figure 3. QET (Quantum Economy Theory)—relation between NSO and PSO.

Groove management is one of outputs GTSD. The theory of Groove management also communicates with existing Stowaway management in which the systemically moves to "second generation management" level.

From the attached figures, a scientific multi-disciplinarily is evident, for example, both general theory of sustainable development and Groove management, string theory, general theory of relativity, and quantum theory, etc.

Through the time period, $\operatorname{Tr}$ can be described and a grasped SD as a whole. SD is the current opportunities for individuals, families, businesses, community, state, and for global economic environment.

Figure 2 shows the interesting period 7,000 years which is characterized by degressive course. What is also interesting on this figure? It is evidently the cyclical orderliness of SD.

Uncovered question remains cycle length $T o$ of SD. It can be assumed to be the length $T r$, which is about 7,000 years. The value of $\mathrm{CI}$ index is an expression of shares of the $\operatorname{Td} / \operatorname{Tr}$ (Figure 2). CI index value of universe $\mathrm{SD}$ is greater than 1.

This figure shows that sustainable development is a natural NSO and PSO cyclical process and declining balance course is its natural cleansing phase. This figure shows the unsustainable assertions or interpretations about the "end of the world", or the end of human civilization.

Figure 3 is one of many figures that deal with QET. This schema shows natural partnership between NSO and PSO. PSO is evidently measurable image of NSO. NSO and PSO group are one whole. 


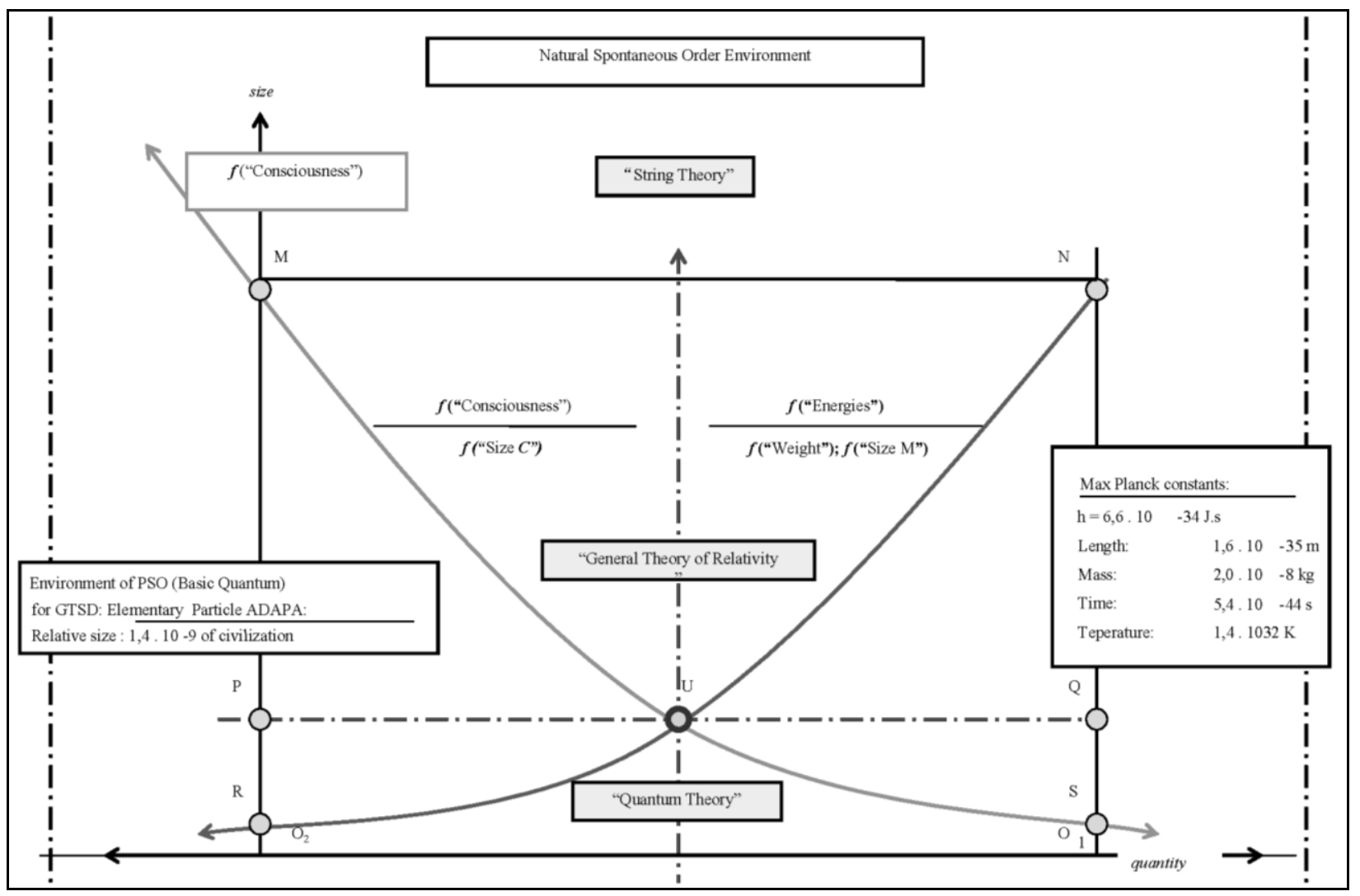

Figure 4. BIT-Fifth theoretical dimension: consciousness.

Trajectory processes PSO subjects take place in NSO space. Internal PSO processes take place in an environment with two variables: order of PSO subject and consciousness of PSO subject.

NSO and consciousness NSO are also new scholarly spaces. "String theory" begins to show us the way to the understanding of NSO environment and communication between NSO and PSO.

It can be assumed that existing metaphysical approach to relations between the NSO and PSO is already outdated.

Figure 4 moves SD within the physics. Great integration creates PSO and NSO.

Max planck PSO environment circumscribed variables such as size, weight, time, and temperature. NSO environment cannot be measured by present exact methods any way. An interesting excursion into the NSO environment is string theory. NSO environment can thus be modeled only by mathematical methods.

Through the fifth theoretical dimension which is the consciousness are general theory of relativity, quantum theory, and general theory of sustainable development (NSO and PSO) as a part of big integration theory for physics and economics.

Big Integration Theory (BIT) brings into GTSD dimension of measurability. Economics thus enters into environment of natural sciences. BIT gives a new quality to the economy, which is a quantum economics theory (QET). QET offers a new elementary particle that is Adapa into economics.

Opportunity institute extends its content about new responsibility institute. Responsibility institute makes sense to any legislative framework. As it is evident from the diagram, the basis for the functionality of this model is the NSO. 
In the decision-making process, NSO can be replaced by "perfection imagination of man". Such a model is built on selfishness and isolation. This model lacks topicality of management information. The whole dimension of responsibility is moving to the standardization of homelessness and unemployment.

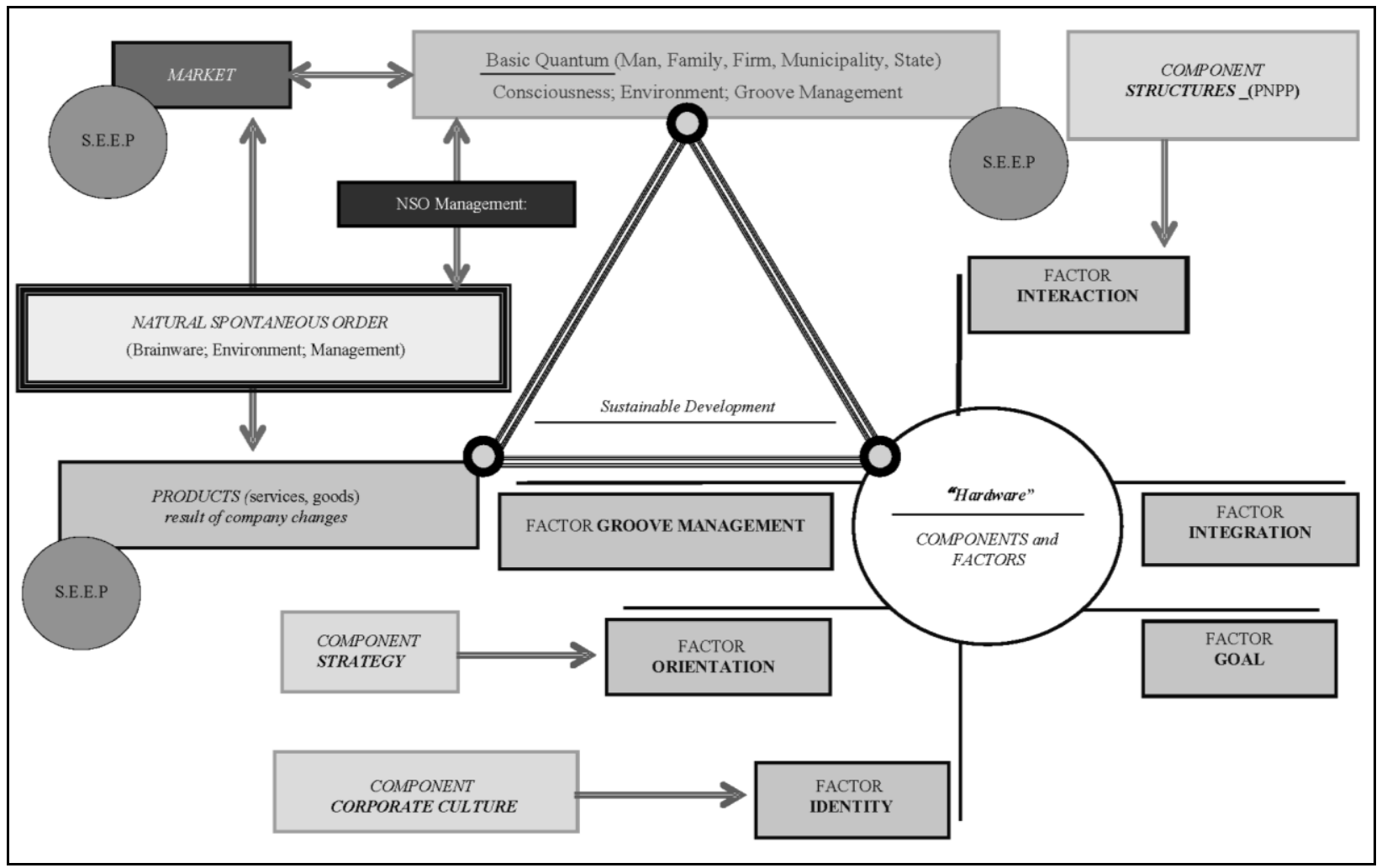

Figure 5. Groove management-Model.

Consciousness integrates currently known elementary particles into one unit. The meaningful integration unit - basic quantum - forms the elementary particle Adapa.

For quantum economics, the man like individuality is basic quantum. On this new basic quantum, processes of sustainable development are experimentally measured and proved.

Size, weight, time, and temperature of the basic quantum Adapa are relative variables, and thus not absolute, for example, the relative size of the elementary particles Adapa $=1.4 \times 10-9$ of civilization.

The current concept of big integration theory can be included into the segment of philosophy of physics. As it is evident from the figure, the fifth dimension follows the trajectory of the size with the expected overlap in the environment NSO.

Environment NSO obviously has the resources not yet known and therefore not utilized. The fifth dimension - consciousness is searched by GTSD, a tool by which NSO resources can be used.

Figure 5 aims management theory to a new level. A firm as basic quantum manages internal and outside processes by Groove management yet unused, because it is too young.

Groove management works with new contents of the factors and components. Factor of orientation thus gains new quality. Corporate culture gets a new ethical content. It contents new order and new responsibilities that will be built on responsibility for the company, customers, partners, etc.. The strategy receives new space which is sustainable development. 


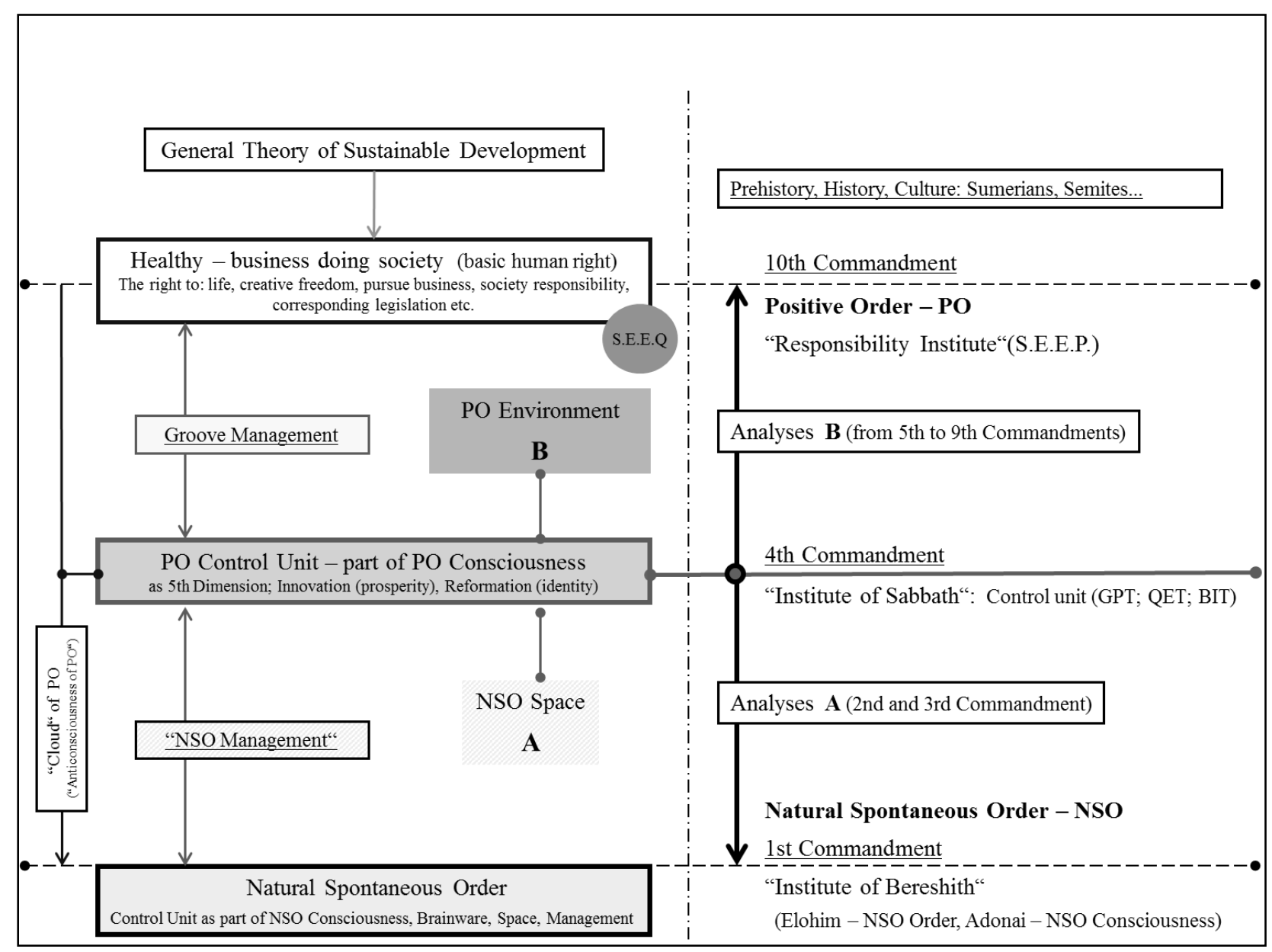

Figure 6. Groove management on historical model.

Groove management will influence the offer of services and products on the market. NSO management disposes multiple communication channels. One of these examples can be channel of information from the market. The NSO communications channels are a new study space for economics.

The basis on which Groove management is built is NSO with its consciousness institute, part of which, for example, are NSO Brainware with NSO management and NSO environment.

Figure 6 accentuates the natural partnership between NSO and PSO. In this figure, comparison of historic and prehistoric perception of communication between the NSO and PSO/PO of man with the current theoretical approach GTSD dominates.

New fifth dimension-consciousness opens up a new environment for the study of NSO and PSO environment. Similarly, the whole communication system is a part of the offered model at this point. The model is natural. GTSD in the offered model works with "cloud" (anticonsciousness) of PSO/PO of man which is a natural part of the NSO environment, too. With this new communication segment, filling the function of the database institute, it works as a BIT. Physical dimension of consciousness institute proves string theory; respectively consciousness institute gives string theory new content or new applications.

The Stowaway management is the product of systemic chaos, madness (Figure 7 and Figure 8). The initiator of this crazy period was socialism and capitalism by the 19th century. A natural part of this crazy 
period is slave communism, fascism, and crazy capitalism with its two world wars and a number of local wars, crises, etc.. The product of this period is, for example, a religious extremism, a political extremism, and terrorism.

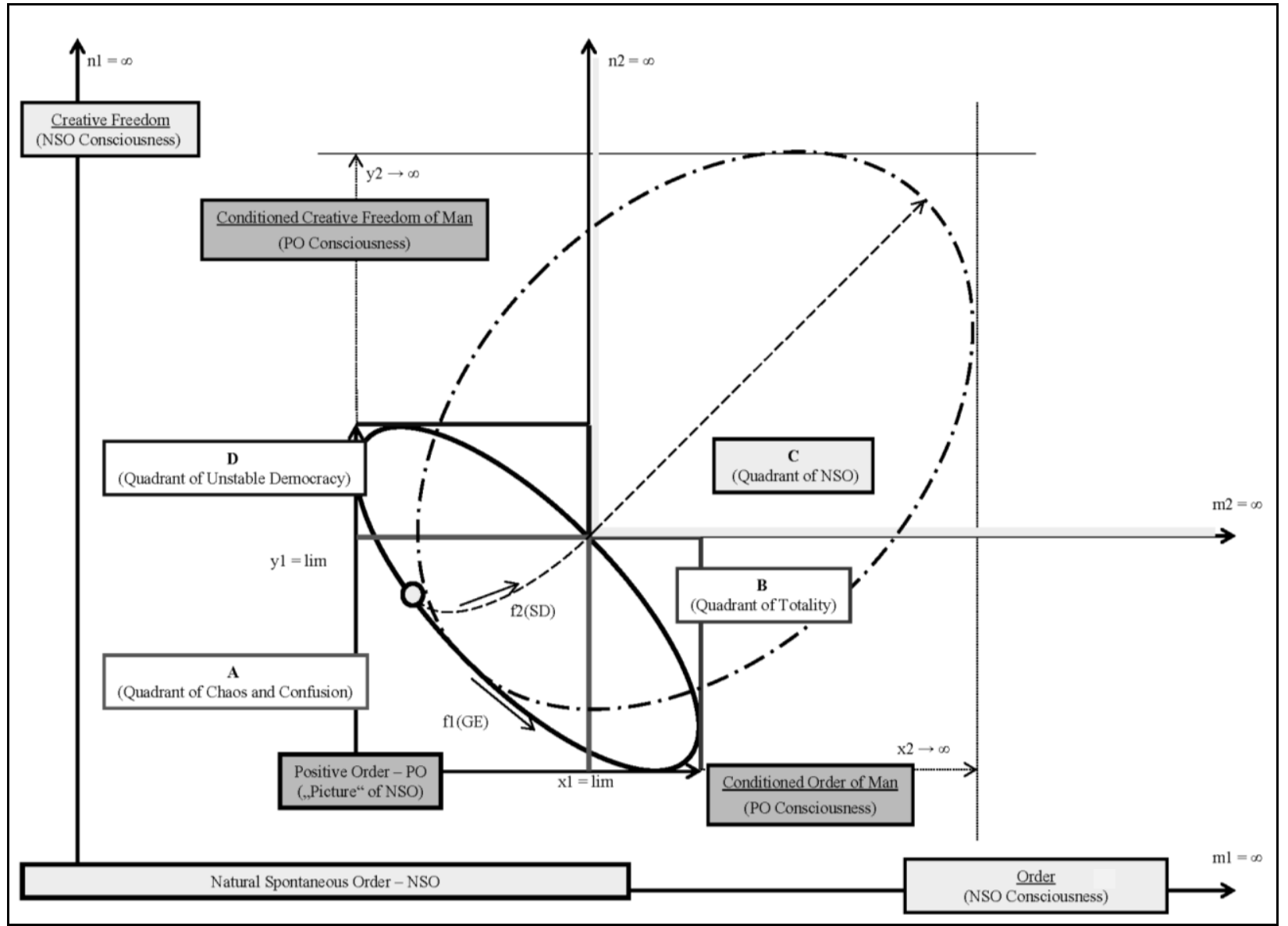

Figure 7. GPT and cyclic processes of change-PO (sustainable development model).

Figure 7 puts a cyclical process PSO of man into a particular space-time. Processes of change generally take place in an environment defined by two variables: order and consciousness. Processes of change take place in four quadrants.

Generally, along with discovered elementary particle, scientists also discover space in which discovered elementary particles are moving. This regularity is also valid for discovered new elementary particle Adapa.

Cycle of change processes circulates on a trajectory connecting the quadrants: A - chaos and craziness of human imagination quadrant, B - totality quadrant, and D — unstable democracy quadrant. Quadrant C - NSO environment is fundamentally different from other PSO quadrants. Thus this paper can speak about variables: order 1 or order 2 and the variables: consciousness 1 or consciousness 2 . Consciousness 2 and order 2 are variables of PSO environment. Consciousness 1 and order 1 are variables of NSO environment.

It is true that the NSO can enter, through its management, into the PSO environments. This regularity in the relations between the NSO and other PSO environments is not applicable to reverse process.

The function $f$ (SDP) - the process of sustainable development — is a reformation process. Its meaning can be found in the final compatibility with SD process. The reformation is a creative process, destroying the 
regressive historical process of changes in PSO environments. Schumpeterian creative destruction is the content only for sustainable development.

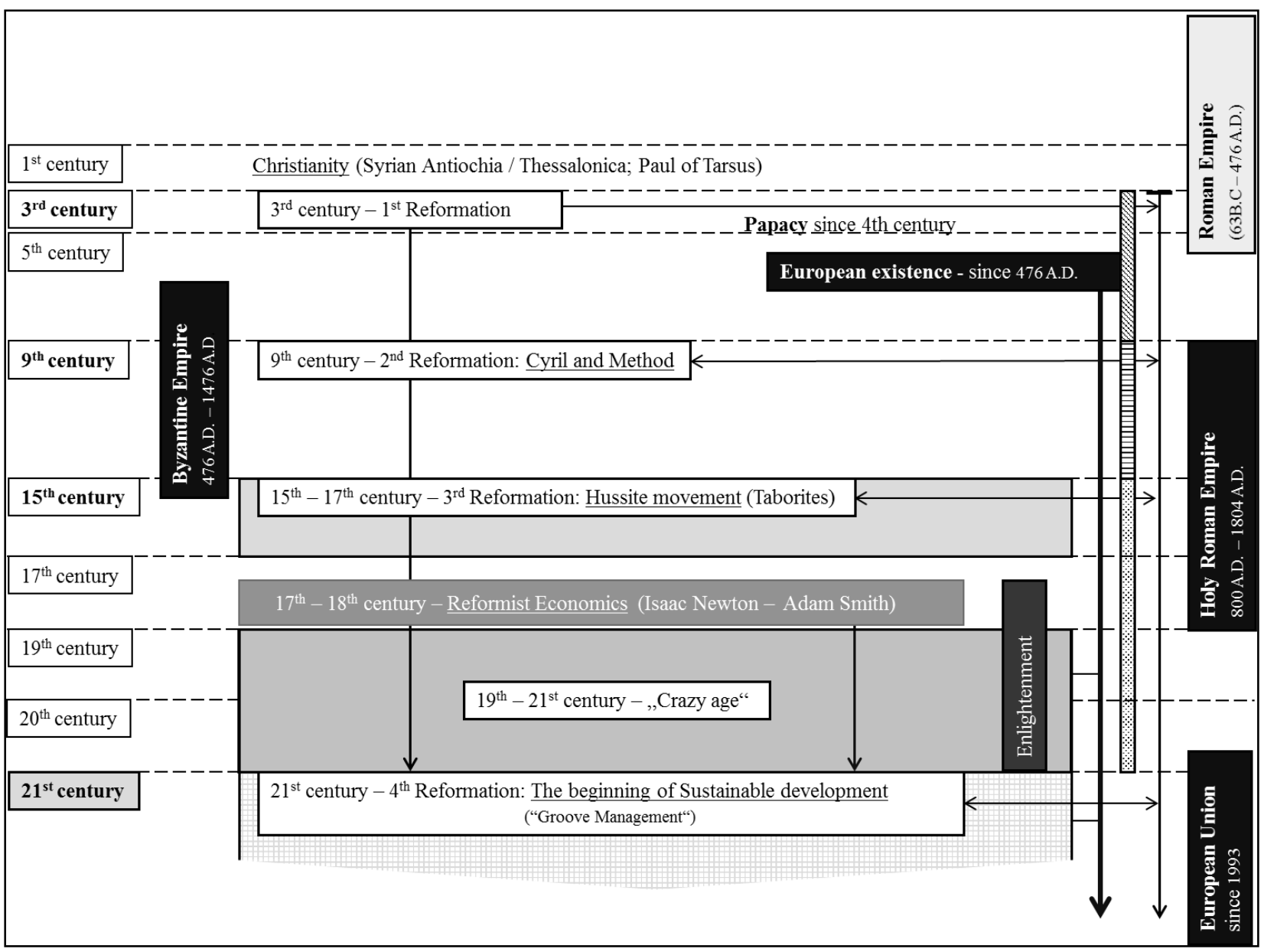

Figure 8. Europe in a historical context-European cycles.

In Figure 8, the content and meaning GTSD are confronted to an example in the Europe from the first century $\mathrm{AD}$ to the present time.

This period can be divided on the period of the Roman Empire and the period after the 476 A.D. as Europe of states, nations, and nationalities. The image of Europe in the cyclic processes is not yet available. It is still lacking structure model that reflects the continuity of the process of change to the period of the Roman Empire. It can be focused, after several years of study, on the history of the reformation. The reformation history has not only unique content, but it also has unique cyclical regularities.

For the past 2,000 years, three reformation periods were in Europe. The first reformation took place in the third century AD. This reformation irreplaceable liquidated the totalitarian regime of the Roman Empire. This reformation survived about 100 years. Corruption was the apparent cause of the end of the first reformation. Emperor Constantine corrupted the Silvestre Bishop of Rome (4th century A.D.). He gave him the economic power, the judicial power, the legislative power, and the executive power. Even the corruption did not save Roman Empire from extinction (467 AD).

The first one who brought Christianity to Europe, according to church tradition, was Paul from Tarsus. He 
was a Jewish scholar with extraordinary wisdom, with top view, with knowledge of Greek and Jewish culture, and with amazing inner creative freedom. His first stop in Europe was Macedonia (Philippi and Thessalonica). From there (ninth century), the entire team came to Great Moravia which was led by brothers Cyril and Methodius.

The second European reformation took place in the ninth century on the territory of Great Moravia. Team of approximately 120 to 150 people led by the brothers Cyril and Methodius transformed Great Moravia territory into a modern, educated, and the competitive country. The second European reformation (in the ninth century) reduced the rose totalitarian up power of the Holy Roman Empire (Charles the Great).

The third European reformation took place in the 15th-17th century. The beginning of the third European reformation movement is generally considered to Taborites in Bohemia. The third reformation has evolved, along with the Waldensians in France and "faithful brethren" in Germany, as pan-European movement.

Although Vaclav IV and his brother Sigmund were not comparable with the figures of Charles IV, Bohemia Kingdom (15th-17th century) was nevertheless the only one freedom country in the rest of totalitarian Europe.

Economically Bohemia was booming economy. Strength of Bohemia Kingdom consisted of the weakness of their kings.

Czech reformation initiated, about 100 years later, the Protestantism in Switzerland and Germany. Protestantism also opposed the totality of the Church and the Holy Roman Empire, which was characterized by corruption. Totalitarian Holy Roman Empire of Germany ended in the inoperable.

\section{Research Result}

Twenty-first century will be the fourth age of the European reformation. The fourth reformation has a chance for its new theoretical content and the current global opportunity to become the third sustainable process of change with its predicted Healthy business doing society, not only for the European Union.

\section{Conclusions}

Groove management is an indispensable tool in the transformation process towards a healthy entrepreneurial society in these segments: social, environmental, economics, and person of man—quality of life.

Healthy business environment is a natural part of sustainable development. It is a natural product of the Civil Society.

General theory of sustainable development could be a basic for future development of science. It could be a tool for a person, community, firm, state and an EU strategy model, too.

The fourth reformation is a function of transformation process from slavery and crazy environments to the natural space of sustainable development (healthy business doing society).

The greatest risk that stands and will stand before a man (decision making institute) and a new entrepreneurial society is the Stowaway management and related sectarianism, formalism, dogmatism, and fanaticism. Those have their roots in our unnatural fascist, slave communist, and crazy capitalist history.

Groove management was also confronted with images of the future entrepreneurial society of Drucker. Conclusions were also confronted with the current processes of change in the EU and works of Schumpeter $(1939,1950,1954)$. 
Universities and NGO's mainly from Europe are starting to cooperate on this transformation project.

\section{References}

Drucker, P. F. (2001): Fungujicí společnost. Praha: Management Press.

Friedman, M. (1962). Capitalism and freedom. Chicago: University of Chicago Press.

Molnár, A. (1991). Valdenští. Praha: Kalich.

Moravec, A. (2004). Ekonomie v globalizačních procesec. Praha: MoreHouse Publishing.

Moravec, A. (2006). Globalizace v souvislostech. Praha: MoreHouse Publishing.

Moravec, A. (2012). Crazy capitalism or sustainable development? Proceedings from First Multidisciplinary Academic Conference in Prague, Praha.

Moravec, A. (2013). Groove management and entrepreneurial society. Proceedings from Mezinárodní vědecká konference, VŠE, Praha.

Pavlík, J. (2001). Adam Smith a teorie spontánniho řádu. Smith, A. Pojednání o podstatě a původu bohatství národů. Praha: Liberální institut.

Schumpeter, J. A. (1939). Business cycles. New York: McGraw Hill.

Schumpeter, J. A. (1950). Capitalism, socialism and democracy. New York: Harper and Brothers.

Schumpeter, J. A. (1954). The theory of economic development. Cambridge: Harvard University Press.

Smith, A. (2001). Bohatství národů. Praha: Liberální institut. 